
Pesquisa

\title{
Sistema DRAI
}

Monitoramento e alerta de secas no Brasil: nova abordagem baseada em um índice de risco

$$
\text { Autor(es): }
$$

Raissa Z. B. Bravo 


\title{
Série dos Seminários de Acompanhamento à Pesquisa
}

\section{Sistema DRAI}

Monitoramento e alerta de secas no Brasil: nova abordagem baseada em um índice de risco

\author{
Autor(es): \\ Raissa Z. B. Bravo
}

CRÉDITOS:

SISTEMA MAXWELL / LAMBDA 


\title{
Raissa Z. B. Bravo
}

\author{
8 período do Doutorado
}

Adriana Leiras e Fernando Cyrino

Gerência da Produção

Logística Humanitária 


\section{Problema de Interesse}

Definição de Seca $\rightarrow$ Desastre

Componentes: ameaça e vulnerabilidade (= risco)

Semiárido brasileiro

Impacto Econômico + Recorrência + Tendência de aumento (Nam et al., 2015)

Sistemas de Monitoramento e Alerta 


\section{Objetivo}

- Desenvolvimento do sistema DRAI (Drought Risk Assessment Interface) de monitoramento e alerta de risco de secas meteorológicas na região do semiárido do Brasil, através da criação de um índice composto, baseado nas componentes ameaça e vulnerabilidade.

\section{Objetivos Secundários}

- Mapeamento do estado da arte sobre ameaça, vulnerabilidade e risco de secas

- Criação e validação de índices compostos para avaliar ameaça, vulnerabilidade e risco de secas no Brasil. 


\section{Metodologia de Pesquisa}

Revisão da Literatura (Thomé et al., 2016)

Índices Compostos (Analytic Hierarchy Process - AHP)

Obs.: Tratamento dos Dados, Normalização, Triangulação, Análise de Sensibilidade

DRAI (C\#, JS, SQL) 


$$
\begin{aligned}
& I A_{i j} \\
& =W_{P} *\left(1-\frac{P_{i j}}{\max (P)}\right)+W_{E T} * \frac{E T_{i j}}{\max (E T)}+W_{T M} * \frac{T M_{i j}}{\max (T M)}+W_{U R} *\left(1-\frac{U R_{i j}}{\max (U R)}\right)+W_{V V} \\
& * \frac{V V_{i j}}{\max (V V)}+W_{I T} * \frac{I T_{i j}}{\max (I T)}+W_{\text {TMin }} * \frac{\operatorname{TMin}_{i j}}{\max (\text { TMin })}+W_{\text {TMax }} * \frac{\operatorname{TMax}_{i j}}{\max (\text { TMax })}
\end{aligned}
$$




\section{Resultados e Validação}

Comparação com outros

mapas 


\section{Geração de Alertas}

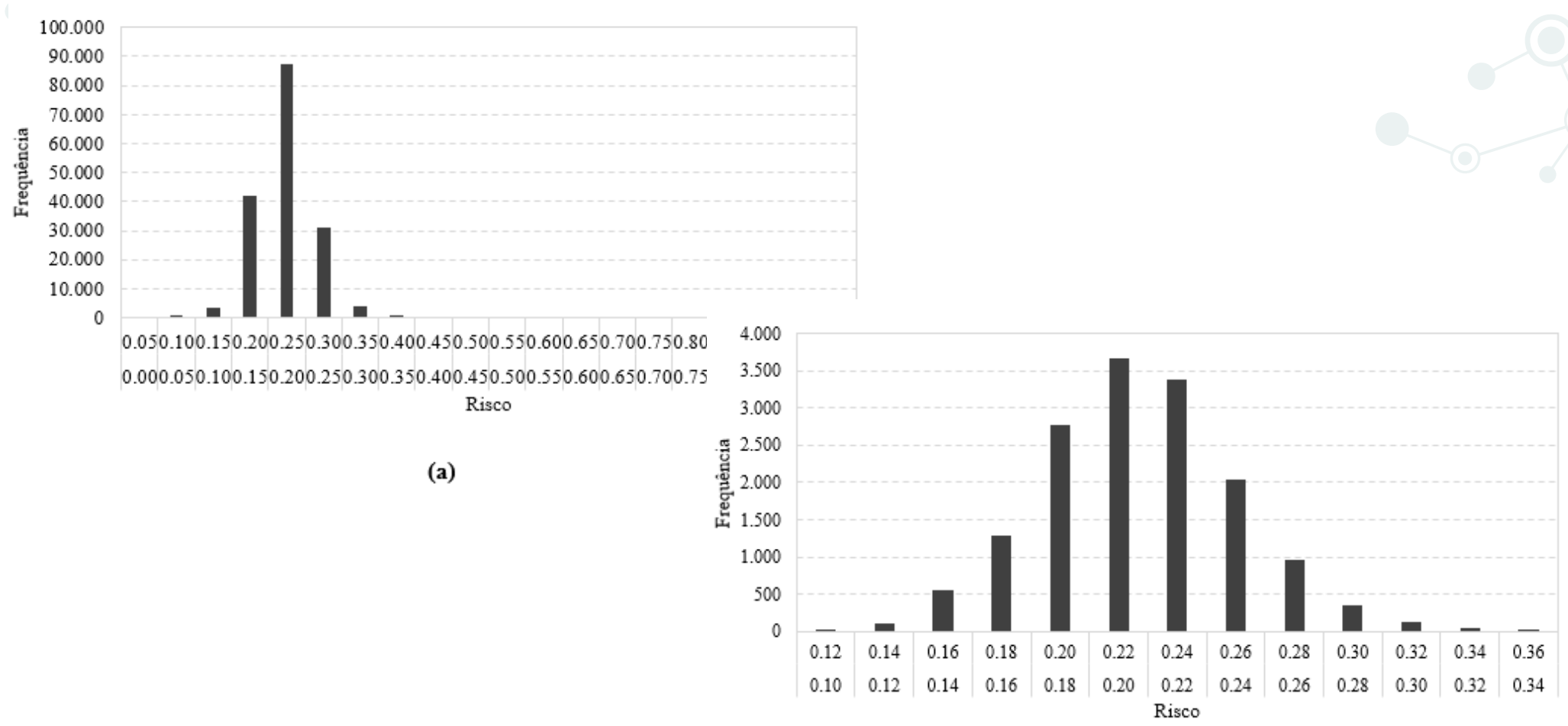

(b) 
https://drai.live/ 


\section{Estratégias de Mitigação}

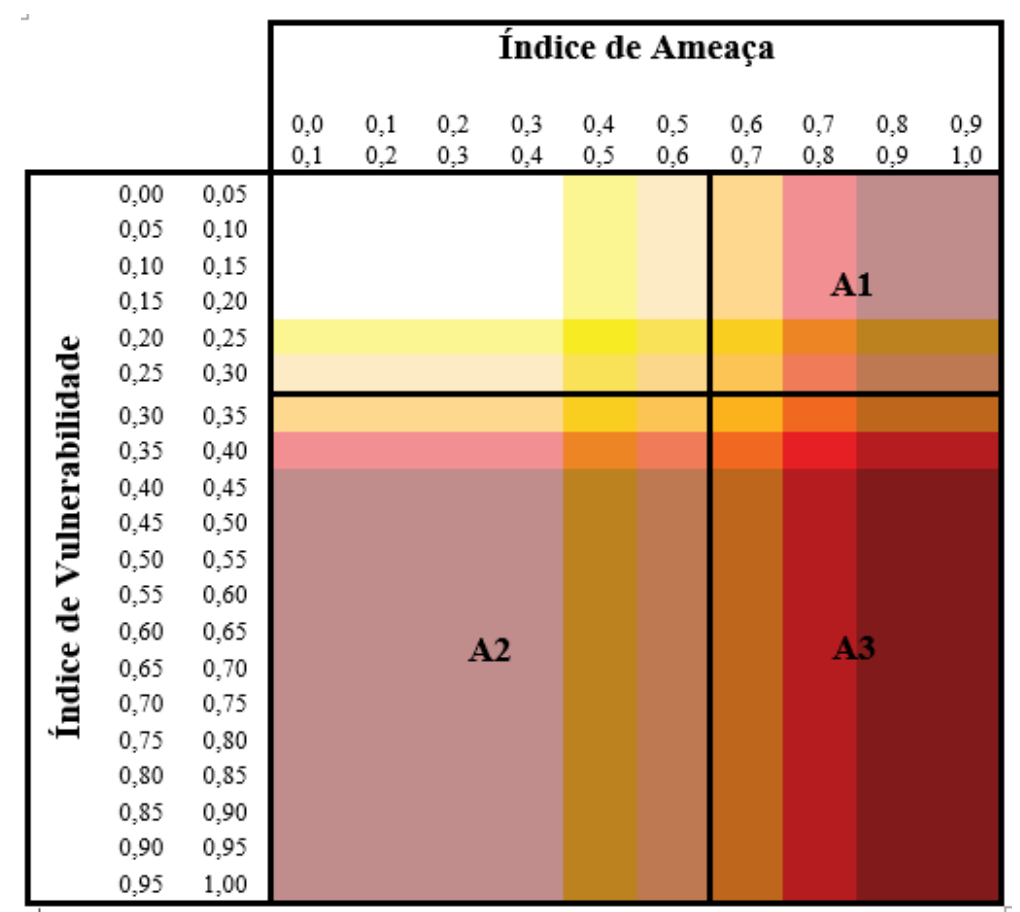

\begin{tabular}{|c|c|c|c|c|}
\hline Alerta & Ameaça & Yulnerab. & Plano de Ação & Responsável \\
\hline \multirow{5}{*}{ A1 } & \multirow{5}{*}{$\begin{array}{l}\text { Acima de } \\
\text { Moderado }\end{array}$} & \multirow{5}{*}{$\begin{array}{l}\text { Abaixo de } \\
\text { Moderado }\end{array}$} & Operação Carro Pipa & SEDEC (MI) \\
\hline & & & Programa Garantia Safra & $\mathrm{MDA}$ \\
\hline & & & Programa Bolsa Estiagem & MI \\
\hline & & & Venda de milho para ração animal a preços subsidiados & $\begin{array}{l}\text { MF, MP, } \\
\text { CONAB, } \\
\text { MAPA }\end{array}$ \\
\hline & & & $\begin{array}{l}\text { Expansão das linhas de crédito de emergência para } \\
\text { agricultores, comerciantes e setores da indústria }\end{array}$ & BNB \\
\hline \multirow{5}{*}{$\mathrm{A} 2$} & \multirow{5}{*}{$\begin{array}{l}\text { Abaixo de } \\
\text { Moderado }\end{array}$} & \multirow{5}{*}{$\begin{array}{l}\text { Acima de } \\
\text { Moderado }\end{array}$} & Cisternas de Água de Chuva & $\begin{array}{l}\text { MI (DNOCS } \\
\text { CODEVASF), } \\
\text { MDS }\end{array}$ \\
\hline & & & Perfuração de Poços & $\mathrm{SEDEC} / \mathrm{MI}$ \\
\hline & & & $\begin{array}{l}\text { Construção de barragens, aquedutos e estações de } \\
\text { bombeamento }\end{array}$ & $\begin{array}{l}\text { DNOCS, } \\
\text { SUDENE, } \\
\text { CODEVASF }\end{array}$ \\
\hline & & & $\begin{array}{l}\text { Instalação de poços profundos de grandes fluxos em } \\
\text { bacias sedimentares }\end{array}$ & MME \\
\hline & & & Renegociação da dívida dos agricultores & BNB \\
\hline A3 & $\begin{array}{l}\text { Acima de } \\
\text { Moderado }\end{array}$ & $\begin{array}{l}\text { Acima de } \\
\text { Moderado }\end{array}$ & Plano de Ação A1 + A2 & \\
\hline
\end{tabular}


$\vdots \because \because \because \because \because$

Publicações 


\section{6 \\ CAPES}

(C) Cemaden

Obrigada!

\section{Hands}

PUC RIO

DEPARTAMENTO DE ENGENHARIA INDUSTRIAL 